\title{
C-sphere strength as an indicator of rolling contact performance of silicon nitride
}

\author{
W. Wang ${ }^{1}$, A. A. Wereszczak ${ }^{2}$ \& M. Hadfield ${ }^{1}$ \\ ${ }^{1}$ School of Design, Engineering and Computing, \\ Bournemouth University, Poole, UK \\ ${ }^{2}$ Material Science and Technology Division, \\ Oak Ridge National Laboratory, Oak Ridge, Tennessee, USA
}

\begin{abstract}
Silicon nitride material has been used as a bearing material due to its superior performance against bearing steel. Its successful application as a bearing element leads to the development of other rolling contact applications in the automotive industry, especially the engine manufacturing industry. Its excellent rolling contact performance can make significant savings on warranty costs for engine manufactures. However, the remaining difficulty for the broader application is the high component machining cost. Further understanding of the rolling contact performance of silicon nitride material in relation to its surface integrity will enable engine manufactures to produce components that meet the design requirements while at the same time reduce the machining cost. In the present study, the relationship between the $\mathrm{C}$-sphere strengths of silicon nitride specimens and their rolling contact fatigue life is investigated. The $\mathrm{C}$-sphere test is designed to compare the strengths of three batches of Sintered and ReactionBonded Silicon Nitride (SRBSN) specimens with different subsurface quality induced by varying the machining parameters. The rolling contact fatigue (RCF) performance of three batches of SRBSN ball specimens are studied on a modified four ball tester. The results show that the most aggressively machined specimens have the weakest $\mathrm{C}$-sphere strength and the shortest RCF life. This positive relationship can give component manufactures a valuable reference when they make selections of candidate material and finishing standards. Keywords: ceramics, silicon nitride, flexure strength, rolling contact.
\end{abstract}




\section{Introduction}

Silicon nitride $\left(\mathrm{Si}_{3} \mathrm{~N}_{4}\right)$ has been used in rolling contact applications in various industries such as turbomachinery, power and automotive industries. Compared with steel traditionally used in these applications, it has significant advantages due to its low density, low friction, corrosion resistance and excellent performance under extreme conditions. However, a major limitation of its wider application is its high material and machining cost, especially the cost associated with the component finishing stage. The high material cost is partly due to the high cost of raw silicon nitride powder, and another contributor is the high energy consumed and the demanding environment involved in the sintering process of high strength $\mathrm{Si}_{3} \mathrm{~N}_{4}$, such as Hot Isostatically Pressed (HIPed) $\mathrm{Si}_{3} \mathrm{~N}_{4}$ [1]. For different types of components with different degrees of machining complicacy, the machining cost can contribute to $55 \%-70 \%$ of the overall component cost [2]. For a $\mathrm{Si}_{3} \mathrm{~N}_{4}$ bearing element, the cost of surface finishing contributes to around $70 \%$ of the overall cost. A Sintered and Reaction Bonded Silicon Nitride (SRBSN) has been developed to reduce the material cost without significant compromise on strength. It uses silicon power as the raw material instead of $\mathrm{Si}_{3} \mathrm{~N}_{4}$ power, and the silicon power is nitrodized through reaction bonding. High density $\mathrm{Si}_{3} \mathrm{~N}_{4}$ is achieved by sintering process after reaction bonding, however, the sintering temperature and pressure is lower than that of HIPed $\mathrm{Si}_{3} \mathrm{~N}_{4}$. In order to materialise the benefit of low cost SRBSN, better understanding of the relationship between the finishing process and the contact reliability is necessary to optimise the machining process and reduce the cost in this stage.

The machining effect on the surface quality of SRBSN has been studied by researchers $[3,4]$. It was found that by changing the grit size of diamond dressed on the grinding wheel, different depth of subsurface damage can be generated on SRBSN rod and bar specimen. It is reported that the size of micro-cracks on the rod specimen generated in grinding process varies from 10-50 microns from 1200 grit to 180 grit diamond dressed grinding wheel. It is important to quantify the surface integrity of SRBSN in relation to its surface strength, and linking the surface strength with rolling contact fatigue performance of the specimen. In the present study, the machining effect on the surface strength and rolling contact fatigue performance of a Ceralloy 147-31N (Ceradyne Inc, United States) SRBSN ball is studied. The surface strength is measured by the compressive Csphere flexure strength.

\section{Ceralloy 147-31N SRBSN and specimen machining}

The micrographs of a Ceralloy 147-31N Si${ }_{3} \mathrm{~N}_{4}$ specimen are shown in Figure 1. The microstructure is polished using diamond suspension, and the size of the diamond paste used in the suspension is gradually reduced from 15 micron to $1 / 4$ micron. The polished surface is plasma etched using a mixture of carbon fluoride and oxygen for 6.5 minutes before it is coated for SEM examination. The darker grey phase in the microstructure is $\beta-\mathrm{Si}_{3} \mathrm{~N}_{4}$, which is the major constituent phase 
in the microstructure. The lighter grey phase, which can be found between the grains boundary is a glassy phase, which is formed by sintering aides (rare earth oxides). The needle-like grains interlock with each other, which are thought to be responsible of improving fracture toughness. However, the relatively long length of the needle-like grains can limit the strength of the material, so a compromise must be struck between desired fracture toughness and strength.

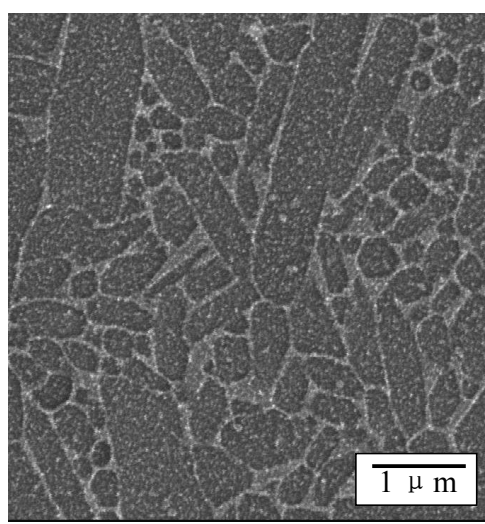

(a)

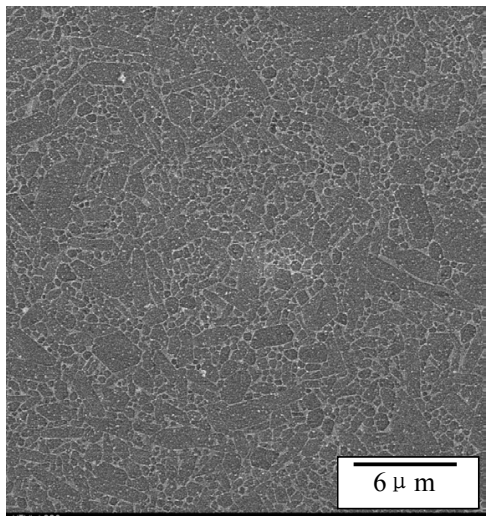

(b)

Figure 1: $\quad$ Microstructure of Ceralloy 147-31N SRBSN after plasma etching.

In order to examine the relationship between rolling contact performance of Ceralloy 147-31N $\mathrm{Si}_{3} \mathrm{~N}_{4}$ and its surface integrity, the as-sintered ingot was machined into three batches (with ten specimens in each batch) of $12.7 \mathrm{~mm}$ diameter balls each having different machining parameters. Table 1 shows the applied machining procedures. These three conditions are referred as coarse, fine and conventional. Roughing, the first step of three step machining process are the same for all three conditions.

Table 1: $\quad$ Machining procedures applied to finish $12.7 \mathrm{~mm}$ diameter balls.

\begin{tabular}{clcc}
\hline Specimen Type & \multicolumn{1}{c}{ Finishing Step } & Diamond Size & Removal \\
\hline \multirow{2}{*}{ Coarse } & 1 (roughing) & accepted practice & \\
& 2 (induce damage) & 100 grit & $0.1000 \mathrm{~mm}$ \\
& 3 (finishing) & 600 grit & $0.0127 \mathrm{~mm}$ \\
\hline \multirow{2}{*}{ Fine } & 1 (roughing) & accepted practice \\
& 2 (induce damage) & 180 grit & $0.1000 \mathrm{~mm}$ \\
& 3 (finishing) & 600 grit & $0.0127 \mathrm{~mm}$ \\
\hline \multirow{2}{*}{ RCF- } & Use the "accepted" practice for RCF finishing (using 180, \\
Conventional & $\begin{array}{l}\text { 220, 320 grit diamond, and 600 and 1200 grit diamond } \\
\text { paste in sequence) }\end{array}$ \\
\hline
\end{tabular}

The second step of the grinding process was intended to produce different depths of machining damage in the ball's near-surface-volume. The variation on 
the second step produces $\mathrm{Si}_{3} \mathrm{~N}_{4}$ ball specimens with different subsurface qualities, such as the depth of subsurface damage, population of the micro-cracks etc. The final step of grinding guarantees that coarse and fine specimens have the same surface roughness. The conventional specimens have a better surface finish by introducing 1200 grit diamond paste on the final finish. Five balls in each batch were tested on a modified four ball tester to compare their rolling contact fatigue performance, and the other five balls in each batch were machined into $\mathrm{C}$-sphere test specimen to examine the variation in hoop tensile strength caused by machining. The design consideration, the geometry of the $\mathrm{C}$-sphere and the loading scenario are explained in the next section.

\section{C-sphere test}

A C-sphere flexure strength test specimen was developed to enable the study of and measurement of surface strength and linked flaw size [5]. The design of the C-sphere specimen was inspired by the C-ring specimen, which is used to evaluate the strength of ceramic tubes [6]. Enabling the identification of a flaw type (usually surface- or near-surface located) and measurement of its size in finished ceramic balls is obviously important for the study of strength, but perhaps more importantly, for the study and predictability of RCF performance (a response limited by surface- or near-surface-located flaws or in changes thereof).

Three batches of Ceralloy 147-31N $\mathrm{Si}_{3} \mathrm{~N}_{4}$ balls with a diameter of $12.7 \mathrm{~mm}$, as described in Table 1 were machined into $\mathrm{C}$-sphere flexure strength specimens, which are shown in Figure 2(a). Grinding of the slot was performed in a two step process using a Type 1F1 diamond plated grinding wheel (127 mm diameter * $6.35 \mathrm{~mm}$ thick $* 3.175 \mathrm{~mm} \mathrm{R}$ ) for the final grinding. The geometry and tolerance of the $\mathrm{C}$-sphere specimen is shown in Figure 3.

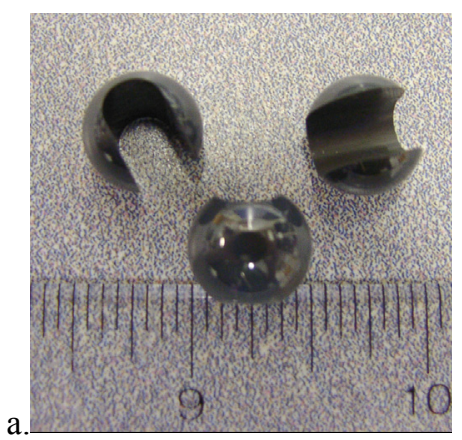

Figure 2: (a) C-sphere specimen before flexure test; (b) C-sphere test loading scenario.

C-sphere flexure specimens were monotonically and compressively loaded to failure using an electromechanical universal testing machine at a crosshead displacement rate of $0.5 \mathrm{~mm} / \mathrm{min}$. The loading scenario is shown in Figure 2(b). 
A special jig was used to horizontally align the C-sphere slot prior to loading. Load to fracture was recorded and combined with the failure load-failure stress relationship from FEA to determine C-sphere flexure strength. Weibull strength distributions were determined using commercially available software. Optical fractography was also conducted on all specimens to identify failure location and the fracture surfaces of a select few specimens were examined with SEM.

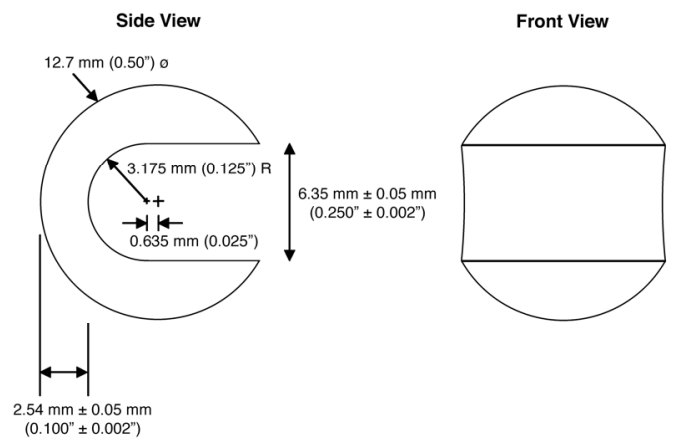

Figure 3: $\quad$ C-sphere specimen geometry.

\section{Rolling contact fatigue test of silicon nitride balls with artificial cracks}

Bearing grade HIPed $\mathrm{Si}_{3} \mathrm{~N}_{4}$ excellent rolling contact performance, however, the RCF performance of SRBSN is less understood. In order to compare the rolling contact performance of coarse, fine, conventional Ceralloy 147-31N $\mathrm{Si}_{3} \mathrm{~N}_{4}$ balls, artificial cracks are created and positioned into the contact path to accelerate the failure of the test specimens. A modified Plint TE 15 impact tester is used to generate the surface cracks. A test specimen is attached to a pendulum, and released at 60 degree angle to collide with a fixed contact ball. The energy absorbed during the contact can be calculated by the potential energy loss of the pendulum. The contact ball used for the artificial crack generation is TSN-03H HIPed $\mathrm{Si}_{3} \mathrm{~N}_{4}$. Figure 4(a) shows the artificial crack under ultra-violet (UV) light after dye penetration. Figure 4(b) shows SEM image of the centre of the crack where the two crack edges have an approximate gap of 2.5 micron.

A modified four ball machine is used to perform the test [7]. Figure 5(a) shows the schematic of modified four ball contact with $\mathrm{Si}_{3} \mathrm{~N}_{4}$ fixed in the collet as upper driving ball and three steel balls in the cup as lower contact balls. The centre of contact path on the upper $\mathrm{Si}_{3} \mathrm{~N}_{4}$ ball situates at $1.17 \mathrm{~mm}$ above the bottom of the ball. In order to classify the position of the crack within the contact path, the positioning parameters of the crack, and some typical positions of the crack are shown in Figure 5(b) [8]. As shown in the schematic, $\beta$ measures the angle between ring crack and the contact path centre line. $2 \mathrm{a}$ is the width of the contact path, and $\mathrm{R}$ represents the radius of the ring crack. $\delta$ measures the distance between the centre of the hypothetic ring crack circle and the centre line 
of the contact path. For all the tests, Castrol 75w90 transmission oil is selected as the lubricant due to the chemical compatibility, potential automotive application of the $\mathrm{Si}_{3} \mathrm{~N}_{4}$ bearing and the lubricant's relatively high viscosity to maintain a lubrication film to reduce the contact between silicon nitride surface asperity and the steel ball surface. The applied Hertzian contact stress between the upper ball and lower balls is $5.6 \mathrm{GPa}$, and the spindle speed is $5000 \mathrm{rpm}$, which results in 11250 stress cycle per minute.

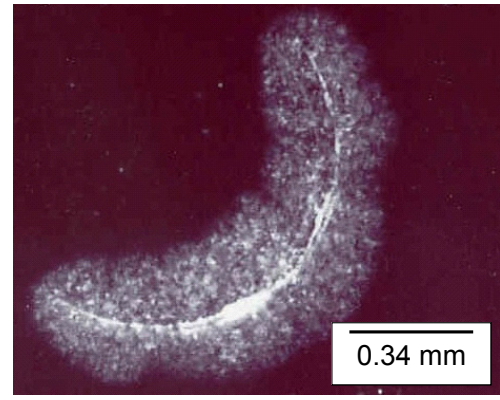

(a)

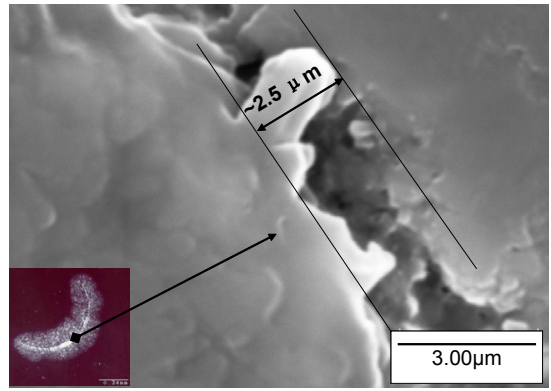

(b)

Figure 4: (a) Visualizing crack under UV light after dye treatment; (b) approximate crack gap size measured in SEM examination.

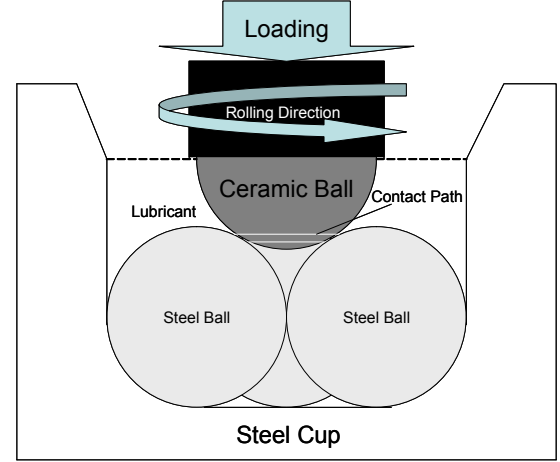

(a)
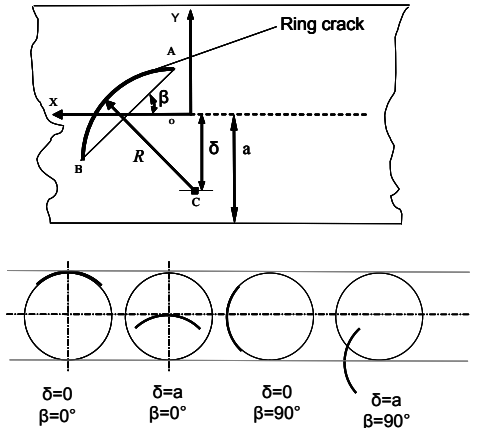

(b)

Figure 5: (a) Schematic of modified four ball test - contact geometry; (b) crack positioning parameter and typical locations of the crack.

\section{Results and discussion}

\subsection{C-sphere strength}

Five C-Sphere specimens machined from each of three batches of coarse, fine and conventional balls were tested. The maximum stress is calculated in ANSYS from the mechanical load used to break the specimens. The two-parameter 
Weibull analysis of the results is show in Figure 6. There is a trend of increasing characteristic strength from coarse, fine to conventional conditions. The coarse specimen has a characteristic strength of $796 \mathrm{MPa}$, while fine and conventional specimens have strengths of $802 \mathrm{MPa}$ and $897 \mathrm{MPa}$ respectively. The fracture surface of a tested C-sphere specimen is shown in Figures 7. Figure 7(a) shows a typical fractography of a ceramic fracture surface, where the fracture origin is identified. The magnified fracture origin is shown in Figure 7(b). According to the $\mathrm{C}$-sphere fractography, the fracture origin is mostly on the surface, sometimes in the near surface area, although it is not necessary to appear on the maximum stress area on the centre of outer fibre of $\mathrm{C}$-sphere specimen. According to Griffith's Criterion, for a fracture toughness of $6 \mathrm{MPa} \sqrt{\mathrm{m}}$ and crack geometry factor of 1.5, the estimate strength limiting flaw sizes are around 27.9, 27.6 and 22.1 microns for coarse, fine and conventional conditions respectively. This result reflects the machining effect on the surface/subsurface integrity of the specimens. Aggressive machining is perceived to generate deeper subsurface damage and higher population of micro-cracks, which are considered to act as one type of the strength limiting flaw. This perception is preliminarily verified by $\mathrm{C}$-sphere flexure test, however, more tests should be done to make such a statistically confident conclusion.

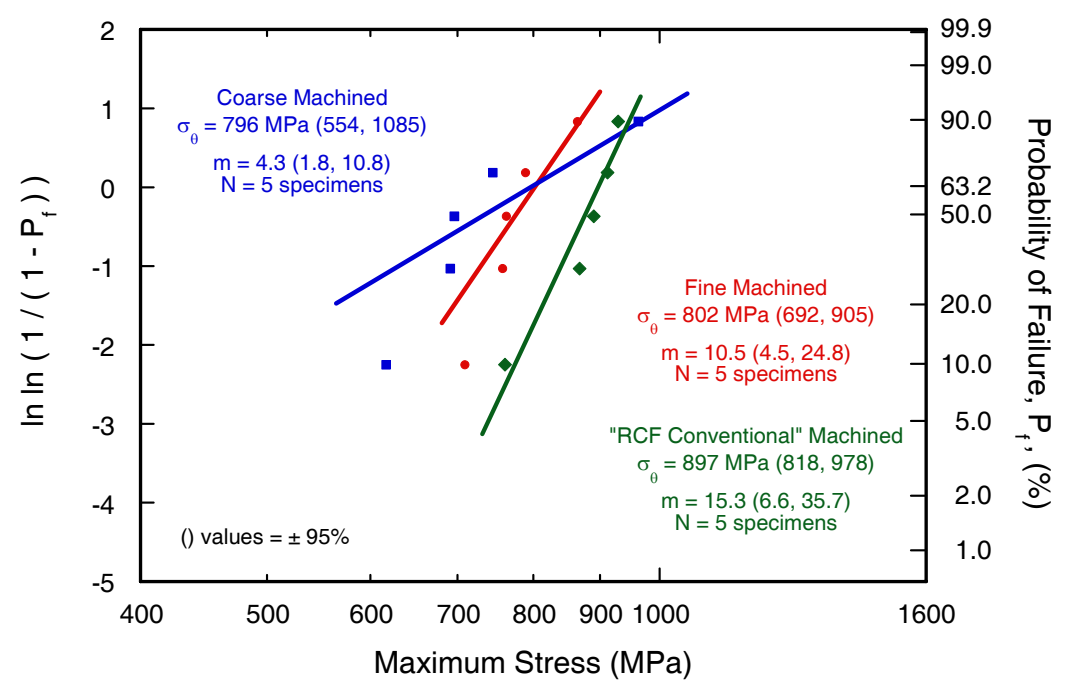

Figure 6: Weibull analysis of C-sphere strength. Values in parentheses represent $\pm 95 \%$ confidence interval.

\subsection{RCF test}

Five balls in each batch of coarse, fine and conventional conditions are tested, and their fatigue lifetimes relative to the positioning parameters are summarised in Table 2. There are two specimens, Fine-05 and Conventional-05, which are 
not positioned accurately in the contact path, and these two specimens are excluded from the analysis. From the Weibull analysis results shown in Figure 8, we can see that conventional specimens show an extended lifetime compared with fine and coarse specimen with identical artificial crack on the surface and cracks positioned in the contact path with the same positioning parameter.
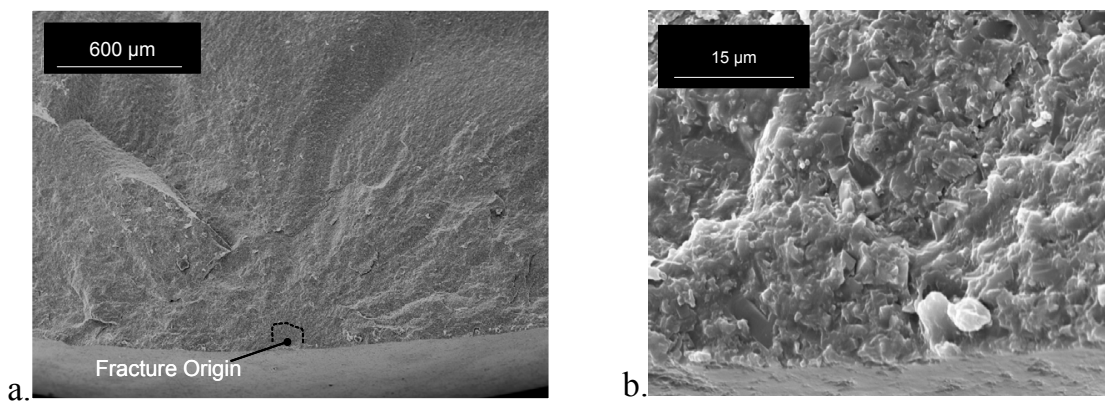

Figure 7: (a) Fractography of $\mathrm{Si}_{3} \mathrm{~N}_{4}$ fracture surface; (b) fracture origin.

Table 2: $\quad$ RCF results of Ceralloy 147-31N SRBSN.

\begin{tabular}{cccc}
\hline Specimen ID & $\begin{array}{c}\text { Crack Position } \\
\text { Parameter } \boldsymbol{\beta}\end{array}$ & $\begin{array}{c}\text { Crack Position } \\
\text { Parameter } \boldsymbol{\delta}\end{array}$ & $\begin{array}{c}\text { Fatigue Life } \\
\text { (No. of Stress } \\
\text { cycles) }\end{array}$ \\
\hline Coarse-01 & $90^{\circ}$ & 0 & $2^{*} 10^{5}$ \\
Coarse-02 & $90^{\circ}$ & 0 & $3.7^{*} 10^{5}$ \\
Coarse-03 & $90^{\circ}$ & 0 & $2.3^{*} 10^{5}$ \\
Coarse-04 & $90^{\circ}$ & 0 & $4^{*} 10^{5}$ \\
Coarse-05 & $90^{\circ}$ & 0 & $3.3^{*} 10^{5}$ \\
\hline Fine-01 & $90^{\circ}$ & 0 & $4.1 * 10^{5}$ \\
Fine-02 & $90^{\circ}$ & 0 & $3.0^{*} 10^{5}$ \\
Fine-03 & $90^{\circ}$ & 0 & $4.2 * 10^{5}$ \\
Fine-04 & $90^{\circ}$ & 0 & $3.4^{*} 10^{5}$ \\
Fine-05 & $90^{\circ}$ & $0.5 \mathrm{a}$ & $1.2^{*} 10^{7}$ \\
\hline Conventional-01 & $90^{\circ}$ & 0 & $4.8^{*} 10^{5}$ \\
Conventional-02 & $90^{\circ}$ & 0 & $8^{*} 10^{5}$ \\
Conventional-03 & $90^{\circ}$ & 0 & $1.5^{*} 10^{6}$ \\
Conventional-04 & $90^{\circ}$ & 0 & $4.5^{*} 10^{5}$ \\
Conventional-05 & $45^{\circ}$ & $0.5 \mathrm{a}$ & suspended \\
\hline
\end{tabular}

The coarse specimen has the worst RCF performance, with a characteristic stress cycles to failure $\mathrm{C}_{\mathrm{f}}=3.4 * 10^{5}$. However, in order to improve the reliability of RCF results, more tests should be run to give a statistically confident conclusion. Figures 9 shows the spall profile of specimens Fine-02 and Conventional-02. Although there are variations on the geometry of the spalls 
from specimen to specimen, there is evidence that secondary cracks are developed in the spalling process.

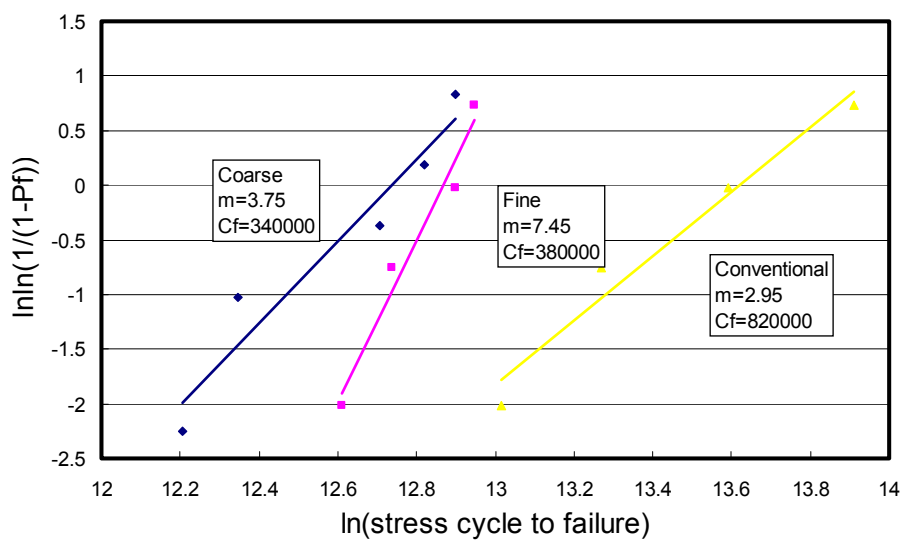

Figure 8: Weibull analysis of RCF test results of coarse, fine and conventional conditions.
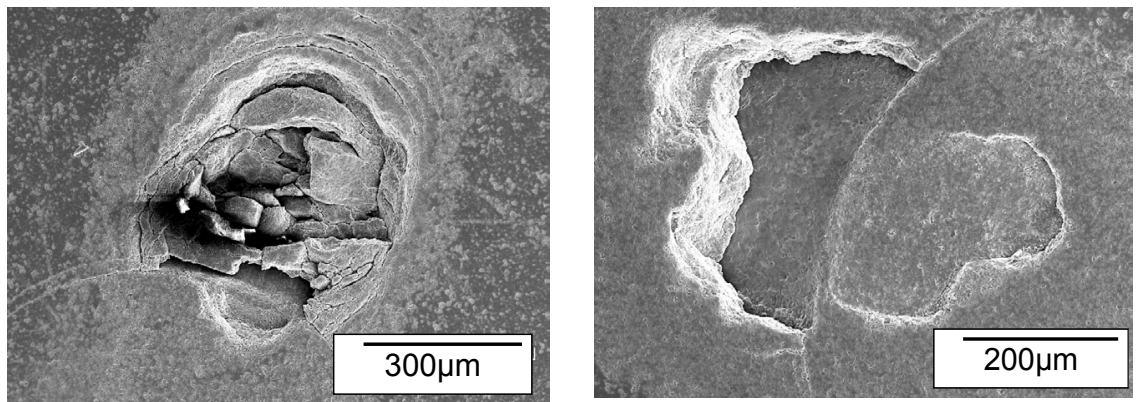

Figure 9: (a) Spall profile of specimen Fine-02; (b) spall profile of specimen Conventional-02.

\subsection{The relationship between $\mathrm{RCF}$ and $\mathrm{C}$-sphere}

The C-sphere and RCF tests reveal the same trend of increasing strength and fatigue life of coarse, fine and conventional specimens. This correlation can be explained by the analysis of stress field of $\mathrm{C}$-sphere specimen and four-ball contact. The failure of the $\mathrm{C}$-sphere specimen is perceived to be micro-crack propagation when the outer fibre is subject to tensile stress. During the specimen machining process, coarse specimens are the most aggressively machined, which result in a higher density and greater depth of induced micro-cracks. As described earlier, the size of the flaw where fracture initiates determine the strength of C-sphere. For the coarse condition, there is a higher probability that deeper strength-limiting flaws (micro-cracks) are located at the maximum tensile 
stress area, and the size of the flaw cause a weaker strength of coarse C-sphere specimen.

In modified four ball test, the upper $\mathrm{Si}_{3} \mathrm{~N}_{4}$ ball is subject to Hertzian contact against the contact ball. For a perfect $\mathrm{Si}_{3} \mathrm{~N}_{4}$ ball without any surface cracks (natural or artificial) positioned in the contact path, the maximum tensile stress generated on the surface due to Hertzian contact is not high enough to initiate a crack. As a result, the RCF life for a perfect $\mathrm{Si}_{3} \mathrm{~N}_{4}$ ball is very long, and it doesn't normally fail within a reasonable testing time (100 million stress cycles). However, for a pre-cracked $\mathrm{Si}_{3} \mathrm{~N}_{4}$ ball, due to the existing of an artificial crack, the stress field on the surface is changed, which is explained in Figure 10(b). There is a gap existing between the two crack edges. For the type of artificial cracks created in the RCF tests in this study, as described earlier, the width of the gap is measured at 2.5 micron. As a result of the gap, when the section of the ball surface to the left of the crack is subject to contact stress, it creates a bending force which generates a tensile stress field on the specimen surface. Together with the stress field created due to Hertzian contact, when the overall tensile stress on the surface reaches a threshold, the micro-cracks will propagate to form a secondary crack on the surface. Due to the existence of a secondary crack, it created a tertiary crack under a similar scenario, and so on so forth, as illustrated in Figure 10(a).

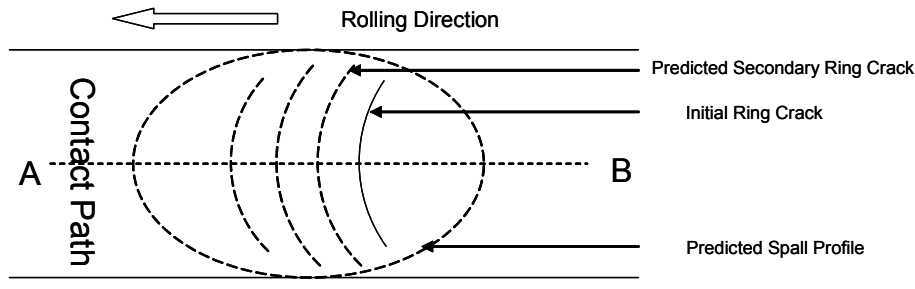

b.

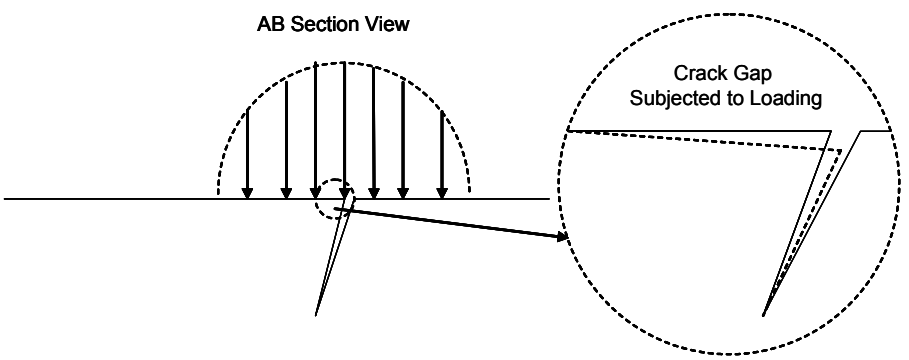

Figure 10: (a) Location of original crack and secondary cracks in the contact path; (b) Mechanism of secondary crack creation.

The secondary and tertiary crack propagates to meet the original crack and meet each other, which form a spall type of failure. Figure 11 shows the secondary cracks of Fine-02 specimen and associated spall failure. The mechanism of forming a secondary crack on the surface in modified four ball test 
is quite similar to micro-crack propagation in C-sphere test when it is interpreted by tensile stress on the surface, which explains the correlation between RCF results and $\mathrm{C}$-sphere results. The boundary element modelling of the artificial crack under Hertzian pressure was carried out by Wang and Hadfield, and the simulation results show the same conclusion $[9,10]$.
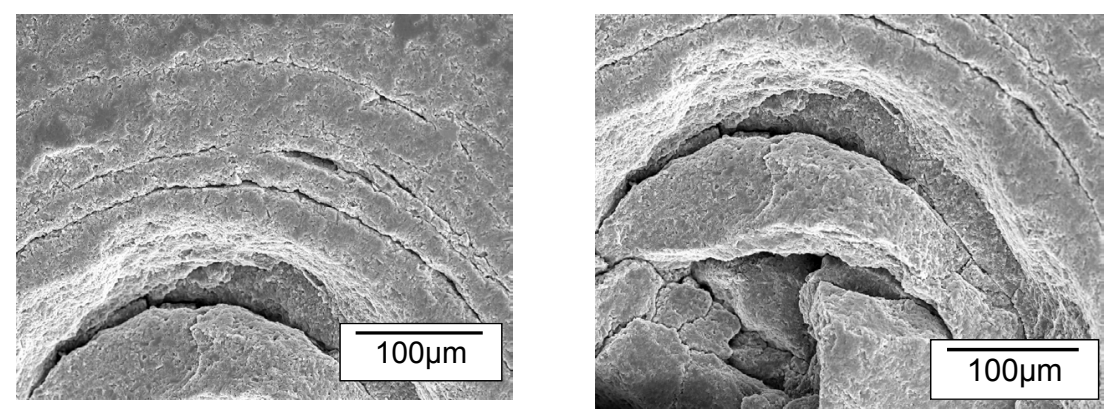

Figure 11: Secondary cracks created on the surface of Fine-02 specimen.

\section{Conclusion}

I. The C-sphere flexure strength results of Ceralloy 147-31N SRBSN show an increased strength comparing from coarsely, fine to conventionally machined conditions.

II. The RCF result reveals an increasing fatigue lifetime among three batches of specimens with the subsurface finished to coarse, fine and conventional condition. The conventional condition shows the longest rolling contact fatigue life, however, the coarse condition has the shortest lifetime under the same test condition.

III. The trend of $\mathrm{C}$-sphere and rolling contact fatigue results are explained by the similarity of the tensile stress field created in Csphere and rolling contact fatigue test which result in the eventual failure. Due to the positive relationship between $\mathrm{C}$-sphere and rolling contact fatigue results, $\mathrm{C}$-sphere strength can be used as a predictor of fatigue lifetime of Si3N4 balls. It can help designers to screen out "weak" candidate silicon nitride material prior to rolling contact fatigue test, which can make reasonable savings on time and cost. Additionally, because flaw types can be identified, Csphere strength testing can be used by $\mathrm{Si}_{3} \mathrm{~N}_{4}$ manufactures and ball finishers to assess the quality of their product.

\section{References}

[1] Riley, F. L., Silicon nitride and related materials, Journal of the American Ceramic Society, 83, pp. 245-265, 2000. 
[2] Effner, U. and Woydt, M., "Slip-rolling and Machining of Engineering Ceramics," BAM, Berlin 259, 2002.

[3] Quinn, G. D., Ives, L. K., and Jahanmir, S., "On the Fractographic Analysis of Machining Cracks in Ground Ceramics: A Case Study on Silicon Nitride," NIST 996, 2003.

[4] Strakna, T. J., Jahanmir, S., Allor, R. L., and Kumar, K. V., Influence of grinding direction on fracture strength of silicon nitride, Journal of Engineering Materials and Technology-Transactions of the Asme, 118, pp. 335-342, 1996.

[5] Wereszczak, A. A., Wang, W., Jadaan, O. M., and Kirkland, T. M., Strength of A C-Sphere Flexure Specimen, Ceramic Science and Engineering Proceedings, 27, pp. 281-293, 2006.

[6] C1323, Annual Book of ASTM Standards, vol. 15.01: ASTM International, 2001.

[7] Tourret, R. and Wright, E. P., Rolling Contact Fatigue Performance Testing of Lubricants: Papers Presented at The International Symposium Organized By the Institute of Petroleum. London: Heydon, 1976.

[8] Wang, Y. and Hadfield, M., Influence of ring crack location on the rolling contact fatigue failure of lubricated silicon nitride: Experimental studies, Wear, 243, pp. 157-166, 2000.

[9] Wang, Y. and Hadfield, M., Life prediction for surface crack initiated contact fatigue of silicon nitride bearing balls, in Tribological Research and Design for Engineering Systems. Amsterdam: ELSEVIER SCIENCE BV, pp. 349-358, 2003.

[10] Wang, Y. and Hadfield, M., A mechanism for nucleating secondary fractures near a pre-existing flaw subjected to contact loading, Wear, 254, pp. 597-605, 2003. 